\title{
Translating futility
}

Cite as: CMAJ 2017 June 12;189:E805-6. doi: 10.1503/cmaj.161354

n Canada and the United States, discussions about futile medical care have obtained a prominent place in the popular consciousness ${ }^{1}$ and in the medical $^{2}$ and bioethical ${ }^{3}$ literatures in recent years. Although there have been efforts to move away from the term "futility" and toward alternatives such as "nonbeneficial"4 or "potentially inappropriate,"5 our experience suggests that futility is still part of the everyday medical vocabulary, and the challenges represented by its use persist. In 2013, a legal case on the withdrawal of "futile" intensive care reached the Supreme Court of Canada, ${ }^{6}$ demonstrating that this issue remains a source of controversy.

So what does "futility" mean, and when should physicians invoke it? In this article, we propose that appealing to "futility" obscures the role of value judgments in everyday medical decision-making, and therefore should be abandoned.

According to the Canadian Oxford Dictionary, futility refers to an act that is "useless, ineffectual." In the medical context, futility has historically been used for interventions that have no possibility of physiologic effect; 8 for example, using orange juice as an anticoagulant. If a patient were to demand such a treatment, a physician would feel very comfortable refusing, and no legal or moral recourse would be expected. These kinds of scenarios are relatively uncommon, in that physicians are not often asked to consider an intervention that is known to have absolutely no chance of achieving a physiologic effect.

In recent decades, references to futility have appeared more commonly in relation to interventions that involve life or death or intensive resource allocation, and when disagreements arise with substitute decision-makers. ${ }^{9}$ Some authors differentiate "quantitative" from "qualitative" futility, ${ }^{10}$ in that quantitative futility applies to interventions that have a very low likelihood of success, and qualitative futility applies to interventions whose goals are of contested value.

Ultimately, we see quantitative futility as collapsing into either physiologic futility when there is really no possibility of biological efficacy, or into qualitative futility when it is an issue of probability.
Let us explain. All interventions are of uncertain effect, and therefore all treatments have only a certain probability of achieving a desired outcome. There is no physiologic or statistical justification to draw a line separating the probability of "futile" versus "non-futile" treatments in any particular place other than with

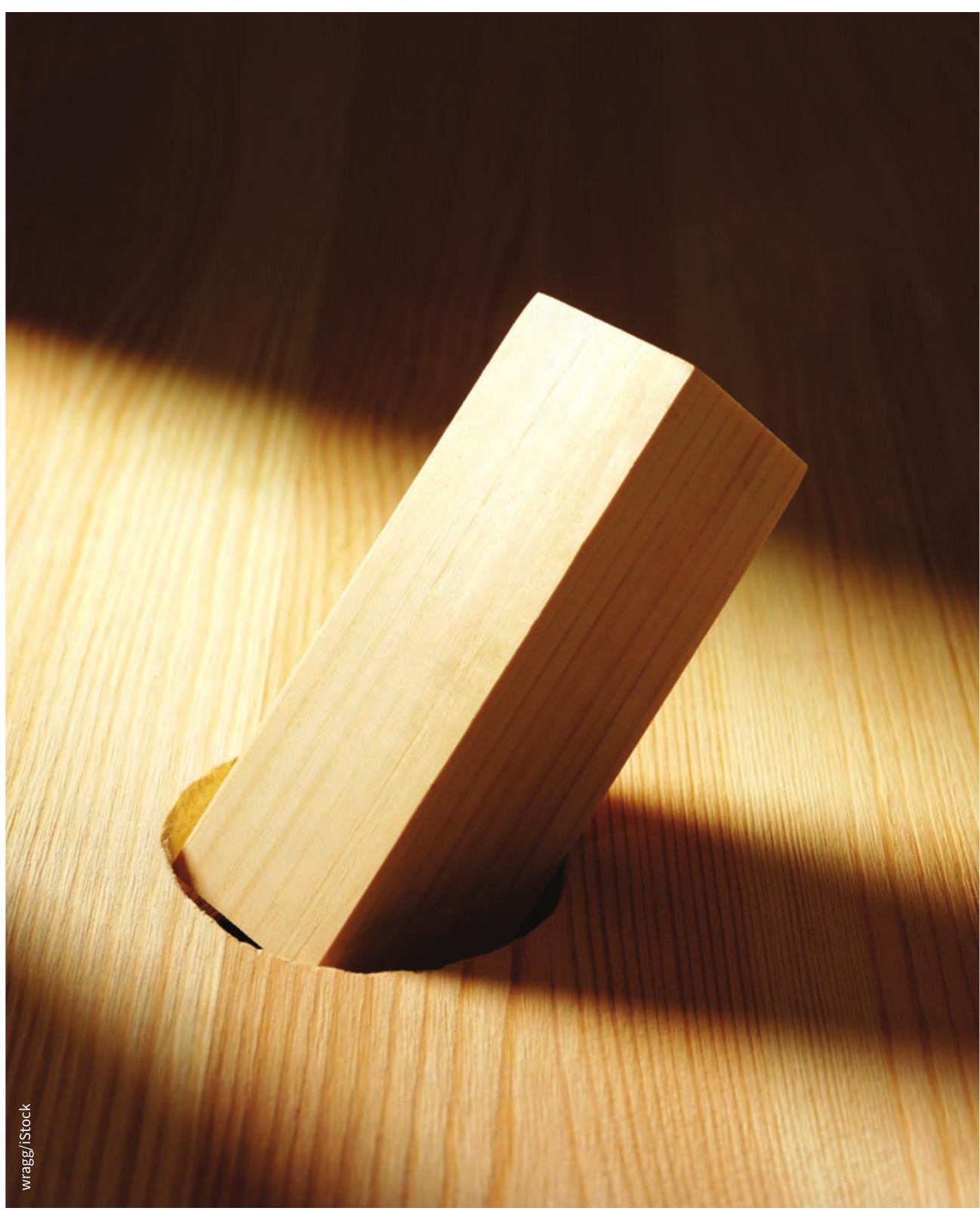


respect to those whose probability is clearly zero. Therefore, any reference to futility other than true physiologic futility is not really a matter of quantification; rather, it is a reflection of the qualitative factors that surround a treatment, such as the patient context and the values of the decision-maker.

Here is an example: a young man has had a cardiac arrest in front of you, and standard treatments have failed to restart his heart. A new treatment has a $1 \%$ chance of working. We would be surprised if a physician invoked futility as a reason not to try the new treatment in this case. However, if the patient were 90 years old, bedbound, with advanced dementia, we might expect exactly that kind of argument. What is the difference between these two scenarios? It is not the intervention or its chance of effect, but rather a judgment about the patient and his or her expected quality of life. In this way, nonphysiologic futility (either quantitative or qualitative) is not only about judging the probability of an outcome, but is also about judging its value.

Let us consider two classic examples of situations in which physicians invoke futility: providing intubation to a 95-year-old person with pneumonia, and withdrawing intubation from a young person with a catastrophic brain injury. It is inaccurate to say that in either individual, ventilation cannot move air through the lungs and cannot prolong life. Moreover, the likelihood that ventilation can achieve these goals is relatively high. The issue is that the life being prolonged may be considered to be of poor quality, and may be of high cost to the health care system. In this case, the physician's use of futility reflects an implicit judgment on quality of life, being couched in terms of physiologic certainty. Therefore, referencing futility can amount to self-deception when physicians apply subjective judgments but pretend to themselves and others - that they are making objective decisions. Relying on appeals to futility can prevent an open and frank conversation about the complexities of the clinical reality.

Use of the term "futility," it would seem, hides the inherent moral content of medical decision-making. Is this moral content specific to cases of end-of-life care and intubation? We would argue not. Medical decision-making is generally consequentialist, in that it is based on evaluating the expected outcomes (benefits and harms) of an intervention. Any evaluation of outcomes requires some ethical framework: that life is better than death, that life without disease is better than life with disease, and that various states of disease or disability may be better or worse than others. Whenever physicians consider the goodness or badness of potential outcomes, whenever they consider what is best for a given patient, they are dealing with questions of ethics. Medical decisionmaking without such a framework is hard to imagine: applying standard algorithms to every scenario, regardless of the clinical context or of patient wishes. This is not how medicine is practised, and nor is this how we think it should be practised.

Where do we go from here? We believe the term "futility" should be abandoned. It is not required in cases of physiologic impossibility, and all other uses are questions of value judgment. Therefore, we would encourage physicians, patients, families, ethicists and administrators to acknowledge the fundamental role of medical uncertainty and ethical judgment in day-to-day clinical decision-making. Physicians should recognize their own values and should not be afraid to share them, because they are honed by their experiences.

Although some patients will prioritize a beating heart over a life of limited awareness, our experience suggests that a frank conversation about what life can realistically be expected to look like helps to bridge many divides over so-called futile care. When clinicians and families remain far apart, this is often a reflection of background family dynamics or strongly held cultural beliefs that may be irreconcilable with modern scientific assumptions.

If we are to draw lines in the sand in terms of which interventions are acceptable in particular patient populations at particular costs, this must be done at the societal level, and will require a difficult process of self-reflection about our collective values. A first step in this process is admitting to ourselves what we mean when we invoke futility.

\section{Paulina Kyriakopoulos MD}

Department of Medicine, University of Ottawa, Ottawa, Ont.

\section{Mark Fedyk PhD}

Department of Philosophy, Mount Allison University, Sackville, NB

\section{Michel Shamy MD MA}

Department of Medicine, University of Ottawa, Ottawa, Ont.

\section{References}

1. Lerner BH. When medicine is futile. The New York Times 2014 Sept. 18. Available: www.nytimes. com/2014/09/19/opinion/when-medicine-is-futile. html (accessed 2016 Nov. 15).

2. Moreno O, Acosta FM, Munoz M, et al. Refusal to ICU admission based on futility. Intensive Care Med Exp 2015;3(Suppl 1):A474.

3. Misak CJ, White DB, Truog RD. Medically inappropriate or futile treatment: deliberation and justification. J Med Philos 2016;41:90-114.

4. Cardona-Morrell M, Kim JCH, Turner RM, et al. Non-beneficial treatments in hospital at the end of life: a systematic review on extent of the problem. Int J Qual Health Care 2016;28:456-69.

5. Bosslet GT, Pope TM, Rubenfeld GD, et al. An official ATS/AACN/ACCP/ESICM/SCCM policy statement: responding to requests for potentially inappropriate treatments in intensive care units. Am J Respir Crit Care Med 2015;191:1318-30.

6. Cuthbertson v. Rasouli, 2013 SCC 53, [2013] 3 S.C.R. 341. 2013 Oct. 18; Available: https://scc-csc. lexum.com/scc-csc/scc-csc/en/item/13290/index. do (accessed 2016 Apr. 13)

7. Canadian Oxford Dictionary. Don Mills (ON): Oxford University Press; 2001.

8. Pope ST. The futility of cardiac stimulation in shock. Cal State J Med 1913;11:499-505.

9. Pope TM. Dispute resolution mechanisms for intractable medical futility disputes. NY Law Sch Law Rev 2014;58:347-68.

10. Schneiderman LJ, Jecker NS, Jonson AR. Medical futility: its meaning and ethical implications. Ann Intern Med 1990;112:949-54.

This article has been peer reviewed 